\title{
Environmental tobacco smoke and stress as risk factors for miscarriage and preterm births
}

\author{
Farha Arffin • Fouad H. AL-Bayaty • \\ Jamiyah Hassan
}

Received: 14 January 2012/ Accepted: 4 June 2012

(C) The Author(s) 2012. This article is published with open access at Springerlink.com

\begin{abstract}
Back ground Exposure of pregnant women to environmental tobacco smoke has been shown to be associated with low birth weight. Many studies have suggested that stress have a role in the etiology of preterm birth.

Aims This study carried out from June 2008 to March 2009 to find the relation between environmental tobacco smoke, stress and miscarriage and preterm births.

Methods A total of 33 subjects consisted of multiparous pregnant women that were in their early third trimester were chosen for this investigation. Subjects were divided into test group women with adverse pregnancy outcome, control group women with successful pregnancy. Four ml of unstimulated whole saliva were collected. The concentrations of cotinine and cortisol were evaluated using commercially available ELISA kit.

Results Pregnancies in which the average standardized cortisol during history of previous miscarriage(s) which occurred within 6th-27th week or/and history of preterm labor which occurred within 28th-36th weeks of gestation, demonstrated higher cortisol level $(1.0201 \pm 0.1855 \mathrm{ng} / \mathrm{ml})$ compared to control group $0.9757 \pm 0.2860 \mathrm{ng} / \mathrm{ml}(P=0.323)$;
\end{abstract}

F. Arffin · F. H. AL-Bayaty ( $\square)$

Faculty of Dentistry, Centre of Studies for Periodontology,

Universiti Teknologi MARA, Level 19, Tower 2, Science and

Technology Complex, 40450 Shah Alam, Selangor, Malaysia

e-mail:drfouadhm@yahoo.com

F. Arffin

e-mail: drfarha@salam.uitm.edu.my

J. Hassan

Department of Obstetrics and Gynecology, Faculty of Medicine,

University of Malaya, Kuala lumpur, Malaysia

e-mail: jamiyah@ummc.edu.my statistical analysis showed no significant differences. Women of control group were more likely to be environmental tobacco smoke exposed $(1.2714 \pm 1.7639 \mathrm{ng} / \mathrm{ml})$ than women with miscarriage and preterm births (0.9889 \pm $0.5498 \mathrm{ng} / \mathrm{ml}$ ).

Conclusion The results from this primarily study demonstrated no association between cotinine, cortisol, miscarriage and preterm births.

Keywords Environmental tobacco smoke $\cdot$ Stress . Miscarriage $\cdot$ Preterm births

\section{Introduction}

There is growing awareness of the harmful effects of smoking during pregnancy. Smoking, through exposure to substances like nicotine and carbon monoxide, is associated with a number of serious complications during pregnancy, including increased rates of spontaneous abortion [1], premature delivery [1, 2] and low birth weight [1]. According to WHO/ICD, miscarriage is defined as the death of fetus before 22 weeks of gestation or a fetus delivered weighing less than $500 \mathrm{~g}$, so the preterm birth will include delivery after 22 weeks and before 37 weeks of gestation.

Exposure of pregnant women to environmental tobacco smoke has been shown to be associated with low birth weight in the infants of exposed non-smoking mothers [2,3], and to have an added negative effect on the infant's birth weight in smoking mothers [2]. Smoking during pregnancy also leads to an increased infant death rate around the time of birth (perinatal mortality) [4], up to one and a half times the average rate [2]. Studies of environmental tobacco smoke (ETS) and risk of spontaneous abortion are limited to a few 
studies of self-reported exposure to ETS or paternal smoke, and the results have been inconsistent [5-7]. Studies based on self-reported ETS exposure probably provide even larger validity concerns than self-reported active smoking and do not properly account for all possible exposures at home, work, and in public places [8,9]. Measurement of cotinine, a biomarker of nicotine, has been shown to be a valid summary measure of the dose received from ETS as well as from active smoking [8-10].

Cortisol is commonly used as a stress marker because its production by the adrenal cortex tends to increase as a result of energetic, immunological, and psychological challenges $[11,12]$. There is growing evidence that psychological, social and economic stresses increase risks of preterm birth and prenatal mortality. It is postulated that stress-induced elevations in cortisol and catecholamine alter the immune response and increase free placental corticotrophin-releasing hormone ( $\mathrm{CRH})$ that may act as an uterotonic agent [13]. Many studies have suggested that stress and stress hormones have a role in the etiology of preterm birth (PTB) [11-13].

Oral fluid has attracted widespread interest as a diagnostic medium for rapid, point-of-care testing [14-16]. Saliva has been considered a "mirror of the body" that generally reflects the state of a patient's overall health. There is growing interest in the use of human whole saliva for diagnostics and disease monitoring as an alternative to blood samples. In contrast to blood, whole saliva is a nonsterile body fluid. Proper handling and storage are required to preserve the integrity of potential biomarkers [17]. The advantages of using saliva for disease diagnostics include ease of access, noninvasive sample collection, increased acceptance by patients, and reduced risks of infectious disease transmission [16]. Oral samples are readily accessible as whole saliva or by sampling secretions from specific glands. The aim of the study was to evaluate the association between ETS and stress as assessed by salivary cotinine and cortisol levels with miscarriage and preterm births.

\section{Materials and methods}

Sample population

This was a cross-sectional study carried out in Malaysia, Kuala Lumpur over 9 months, from June 2008 to March 2009. A total of 250 pregnant women who had their antenatal check-up at the Antenatal Clinic, University Malaya Medical Centre (UMMC) were examined prior to being referred to The Periodontal Postgraduate Clinic, Faculty of Dentistry, University of Malaya for saliva collection. Sixty-three subjects who fulfilled a set of inclusion and exclusion criteria were only eligible for this study.

Thirty-three volunteered pregnant women agreed to participate in this study. Women gave informed consent for all aspects of the study, which was approved by the Ethical Committee. The study protocol was approved by The Medical Ethics Committee of UMMC (No: 607.1) and The Ethical Committee Board of the Faculty of Dentistry, University of Malaya (No: DF OP0706/0029 (P), a).

Medical records

The medical records of all subjects were gathered from the Antenatal Clinic of UMMC. The information collected included history of previous pregnancy, expected date of delivery (EDD), patient's medical status and presence of gestational diabetes in current pregnancy. The presence of serious medical or systemic condition will exclude sample participation in the study.

Based on the information in the medical records, subjects were divided into two groups:

1. Test group: Women with miscarriage and preterm births, 18 of healthy pregnant women who had history of previous miscarriage(s) which occurred within 6th27 th week or/and history of preterm labor which occurred within 28th-36th week of gestation.

2. Control group: Women with successful pregnancy, 14 healthy pregnant women who had no previous miscarriage or preterm delivery at more than 36 weeks.

\section{Inclusion and exclusion criteria}

Thirty-three pregnant women registered at the Antenatal Clinic, UMMC aged between 23- and 39-years old were selected for the study. The inclusion criteria were gestational age between 24 and 32 weeks and multiparous. The exclusion criteria were: smoking active or passive at work or at home, drug abuse such as prednisone, dexamethasone, medical or systemic conditions such as cardiovascular disease, respiratory problem, diabetes mellitus, kidney disease, hematological disorder and other chronic diseases, gestational diabetes and multiple foetuses.

The selected subjects were asked to fill a questionnaire which included information on age, ethnicity, EDD, current body weight, gestational weight gain, occupation, and pregnancy history. Subjects were asked to spit into sterile plastic tubes to collect $4 \mathrm{ml}$ of unstimulated whole saliva which was then kept frozen at $-80{ }^{\circ} \mathrm{C}$ until analyzed. The collection of the saliva was standardized before 12:00 p.m. to avoid differences caused by circadian rhythm. 
Enzyme-Linked Immunosorbent Assay Technique (ELISA)

The concentrations of cotinine and cortisol from the saliva samples were evaluated using commercially available ELISA kit (NANO LIFE QUEST SDN. BHD. SIGMA, GERMANY). ELISA technique is a biochemical procedure to detect the presence of an antibody or antigen from any sample such as plasma, vaginal fluid or saliva. Basically, this technique involves an affixation of an antigen of unknown amount to a microwell surface which has been pre-coated with an antibody specific for the antigen in question.

\section{Statistical analysis}

Statistical Package for Social Science (SPSS) Version 16.0 was used to analyze the results. Since the cotinine and cortisol levels in the saliva displayed a non-normal distribution, the Mann-Whitney test was used to determine the significance of the difference between the test and control groups, for which the statistical significance was set for a $p$ value of $\leq 0.05$.

\section{Results}

Sample population

A total of 33 subjects consisted of multiparous pregnant married Malaysian women (Malayan ethnicity) that were in their early third trimester were chosen for this investigation. The age range of the subjects was between 23- and 39 -years old with a mean age of $29.8( \pm 3.6)$ years. The mean age for the test group was 29.3 and for control group was 30.7. All subjects were Malay government employers. Women with miscarriage and preterm births and women in successful pregnancy group had approximately the same age. Table 1 showed the demographic distribution of the sample.

Results demonstrated that saliva cotinine level was higher in control group $(0.7485 \pm$ SEM $0.1589 \mu \mathrm{g} / \mathrm{ml})$ compared with test group $(0.6776 \pm$ SEM $0.2658 \mu \mathrm{g} / \mathrm{ml})$. Women control group were more likely to be ETS-exposed than women with miscarriage and preterm births. statistical analysis showed no significant differences (Table 2). Figure 1 demonstrates the comparative history of miscarriage and preterm births according to ETS-exposed by evaluating cotinine level in both groups. There were two outliers in test group and one outlier in control group. The level of cotinine for these three outliers is very much low compared to other subjects in each group. Results also show no significant differences.
Table 1 Sample population between test and control groups

\begin{tabular}{llll}
\hline & $\begin{array}{l}\text { Total } \\
\text { sample }\end{array}$ & $\begin{array}{l}\text { Test group } \\
(n=20)\end{array}$ & $\begin{array}{l}\text { Control group } \\
(n=13)\end{array}$ \\
\hline $\begin{array}{l}\text { Age } \\
\text { Race }\end{array}$ & 33 & $29.3 \pm 4.0$ & $30.7 \pm 3.0$ \\
$\begin{array}{l}\text { Malay } \\
\text { Marital status }\end{array}$ & 33 & $20(100 \%)$ & $13(100 \%)$ \\
$\begin{array}{l}\text { i. Single } \\
\text { ii. Married }\end{array}$ & 33 & 0 & 0 \\
Gestational weight & 33 & $33(100 \%)$ & $33(100 \%)$ \\
$\quad$ increment & & & \\
i. $<5 \mathrm{~kg}$ & & 1 & 2 \\
$\begin{array}{l}\text { ii. 6-10 kg } \\
\text { iii. } 10-20 \mathrm{~kg}\end{array}$ & & 7 & 6 \\
iv. 20-30 kg & 3 & 4 \\
v. $>30 \mathrm{~kg}$ & & 4 & 0 \\
Gestational age upon & 33 & 0 & 1 \\
$\quad$ examination & & weeks & weeks \\
\hline
\end{tabular}

Table 2 Cotinine level in test and control groups

\begin{tabular}{lcclc}
\hline Group & $n$ & Mean \pm SEM $(\mu \mathrm{g} / \mathrm{ml})$ & Median $(\mu \mathrm{g} / \mathrm{ml})$ & $p$ value \\
\hline Test & 20 & $0.6776 \pm 0.2658$ & 0.7150 & $0.598^{*}$ \\
Control & 13 & $0.7485 \pm 0.1589$ & 0.8200 & \\
\hline
\end{tabular}

* Mann-Whitney Test

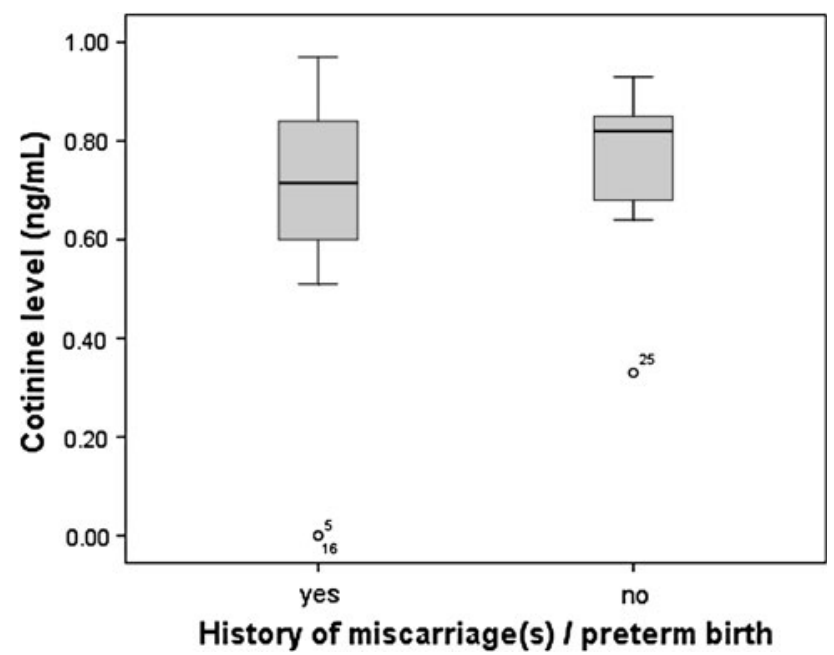

Fig. 1 Level of cotinine verses history of miscarriage and preterm births

We calculated the comparative history of miscarriage and preterm births according to cortisol exposure. Pregnancies in which the average standardized cortisol during history of previous miscarriage(s) which occurred within 6th-27th week or/and history of preterm labor which occurred within 28th-36th weeks of gestation, demonstrated higher cortisol 
level $(1.016 \pm$ SEM $0.182 \mu \mathrm{g} / \mathrm{ml})$ compared to control group $0.978 \pm \mathrm{SEM} 0.298 \mu \mathrm{g} / \mathrm{ml} \quad(P=0.392)$, normal morning levels of saliva cortisol is $0.99 \pm 0.42 \mu \mathrm{g} / 100 \mathrm{ml}$, however, statistical analysis showed no significant differences. [Table 3, Fig. 2]. As for the cotinine, there were also outliers in each group. However, the levels of cortisol for these outliers were higher compared to other subjects in the groups.

\section{Discussion}

To our knowledge, there are a few studies on the relation between ETS and stress as risk for miscarriage and preterm births based on cotinine and cortisol measurements. In recent years, there has been growing knowledge and awareness of the dangers and serious adverse health effects of environmental tobacco smoke exposure. Non-smokers hotel workers in London show saliva cotinine level $(0.5 \mathrm{ng} / \mathrm{ml})$ [18]. The health hazards of environmental tobacco smoke exposure affect almost every organ and system in the body with a wide spectrum of ailments and diseases, and it has been clearly implicated as the cause of death in many of those who were exposed to it [19]. Environmental tobacco smoke exposure acquires special importance when it comes to considering the negative health impact on children.

Table 3 Cortisol level in test and control groups

\begin{tabular}{lllll}
\hline Group & $n$ & Mean \pm SEM $(\mu \mathrm{g} / \mathrm{ml})$ & Median $(\mu \mathrm{g} / \mathrm{ml})$ & $p$ value \\
\hline Test & 20 & $1.016 \pm 0.182$ & 0.977 & $0.392^{*}$ \\
Control & 13 & $0.978 \pm 0.298$ & 0.932 & \\
\hline
\end{tabular}

* Mann-Whitney Test

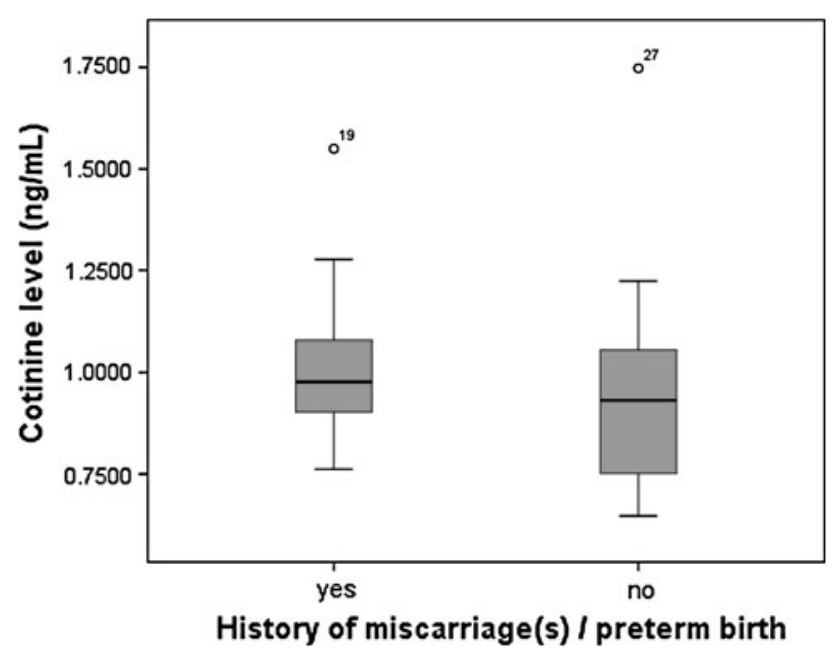

Fig. 2 Level of cortisol verses history of miscarriage and preterm births
There is much evidence to show that smoking complicates the course of pregnancy, endangers the life of the mother, threatens the life of the fetus, and places the newborn at great risk of immediate and long-term complications, and possibly even death [20].

We found that women with successful pregnancy and women with miscarriage and preterm births were exposed to ETS. We decided a priori to exclude smoking women and women using oral snuff or nicotine replacement therapy. Our finding showed that women with successful pregnancy outcome represent higher level of cotinine in their saliva samples. Statistical analysis could not show a significant differential effect of exposure to ETS. This may because the power to study miscarriage and preterm births was limited, because our sample included only 13 cases with normal and 20 with abnormal pregnancy. The biologic mechanisms underlying a possible association between ETS and miscarriage and preterm births may involve pathways similar to those for active smoking, because side stream tobacco smoke contains many of the same constituents as mainstream tobacco smoke [18]. Several components of tobacco smoke (e.g, nicotine, carbon monoxide, and cyanide) are toxic for the developing fetus. Nicotine has vasoconstrictive effects leading to reduced placental blood flow [19]. Carbon monoxide binds to hemoglobin, causing maternal and fetal hypoxia, which may interfere with the development of the growing fetus and induce fetal death. Research indicates that later in pregnancy, smoking does appear to decrease the placenta's ability to deliver nutrients to the developing baby. In addition to potentially causing miscarriages, this can cause babies to be born with lower birth weight and can also increase the risk of stillbirth, as well as death in the first year of life $[18,20]$.

Researchers found that 90 percent of women, whose ages ranged from 18 to 34 , with elevated levels of the stress-induced hormone miscarriage during the first 3 weeks of pregnancy, compared to 33 percent of those with normal levels. Researchers suggest that the body may recognize elevated cortisol levels as an alarm that conditions are unfavorable for pregnancy [21, 22].

Maternal stress is commonly cited as a potential cause for at least part of pregnancy losses that remain "unexplained" [21-23]. Yet, for humans, little physiological evidence exists in support of this hypothesis [24, 25].

Our finding of an association between increased maternal cortisol and higher risk of miscarriage and preterm births, together with previous research has failed to find such an association [25]. Cortisol secretion can be affected by circadian rhythms, physical activity, food consumption, smoking, caffeine, alcohol, and steroid medications [26-28]. None of our participants smoked or consumed alcohol. Cortisol levels may be affected by age [29]; the lack of an effect of age on cortisol may be due to the youthfulness of our 
sample. The 32 women who conceived during the study ranged from 23 to 39 years, but the age distribution was heavily weighted toward the early twenties.

\section{Conclusion}

Results demonstrated no association between cotinine, cortisol miscarriage and preterm births. Future longitudinal studies with larger samples will be necessary to compare cortisol and cotinine levels as risk factors for miscarriage and preterm births across the entire duration of gestation. Further research will also be necessary to explore the physiological pathways that might mediate the observed association.

Acknowledgments The authors express gratitude to the University Teknologi Mara for the financial support DANA Grant 5/3/DST (306/ 2011).

\section{Conflict of interest None.}

Open Access This article is distributed under the terms of the Creative Commons Attribution License which permits any use, distribution, and reproduction in any medium, provided the original author(s) and the source are credited.

\section{References}

1. Lambers DS, Clark KE (1996) The maternal and fetal physiologic effects of nicotine. Semin perinatol 20(2):115-126

2. Andres RL, Day MC (2000) Perinatal complications associated with maternal tobacco use. Semin Neonatol 5(3):231-241

3. Mongelli M, Gardosi J (2000) Fetal growth. Curr Opin Obstet Gynecol 12:111-115

4. Ahlborg G, Bodin L (1991) Tobacco smoke exposure and pregnancy outcome among working women. A prospective study at prenatal care centers in Orebro County, Sweden. Am J Epidemiol $133: 338-347$

5. Windham GC, Swan SH, Fenster L (1992) Parental cigarette smoking and the risk of spontaneous abortion. Am J Epidemiol 135:1394-1403

6. Chatenoud L, Parazzini F, Di Cintio E, Zanconato G, Benzi G, Bortolus R, La Vecchia C (1998) Paternal and maternal smoking habits before conception and during the first trimester: relation to spontaneous abortion. Ann Epidemiol 8:520-526

7. Windham GC, Von Behren J, Waller K, Fenster L (1999) Exposure to environmental and mainstream tobacco smoke and risk of spontaneous abortion. Am J Epidemiol 149:243-247

8. Venners SA, Wang X, Chen C, Wang L, Chen D, Guang W, Huang A, Ryan L, O'Connor J, Lasley B (2004) Paternal smoking and pregnancy loss: a prospective study using a biomarker of pregnancy. Am J Epidemiol 159:993-1001

9. Jarvis M, Tunstall-Pedoe H, Feyerabend C, Vesey C, Salloojee Y (1984) Biochemical markers of smoke absorption and self reported exposure to passive smoking. J Epidemiol Commun Health 38:335-339
10. Haddow JE, Knight GJ, Palomaki GE, Kloza EM, Wald NJ (1987) Cigarette consumption and serum cotinine in relation to birthweight. BJOG: Int J Obstet Gynaecol 94:678-681

11. Benowitz NL (1996) Cotinine as a biomarker of environmental tobacco smoke exposure. Epidemiol Rev 18:188-204

12. Sandman CA, Glynn L, Schetter CD, Wadhwa P, Garite T, Chicz-DeMet A, Hobel C (2006) Elevated maternal cortisol early in pregnancy predicts third trimester levels of placental corticotropin releasing hormone $(\mathrm{CRH})$ : priming the placental clock. Peptides 27:1457-1463

13. Hobel CJ, Dunkel-Schetter C, Roesch SC, Castro LC, Arora CP (1999) Maternal plasma corticotropin-releasing hormone associated with stress at 20 weeks' gestation in pregnancies ending in preterm delivery. Am J Obstet Gynecol 180:S257-S263

14. McLean M, Bisits A, Davies J, Walters W, Hackshaw A, Voss KD, Smith R (1999) General obstetrics and gynecology-fetusplacenta-newborn-predicting risk of preterm delivery by secondtrimester measurement of maternal plasma corticotropin-releasing hormone and a-fetoprotein. Am J Obstet Gynecol 181: 207-215

15. Mandel ID (1990) The diagnostic uses of saliva. J Oral Pathol Med 19:119-125

16. Choo RE, Huestis MA (2004) Oral fluid as a diagnostic tool. Clin Chem Lab Med 42:1273-1287

17. Thomadaki K, Helmerhorst E, Tian N, Sun X, Siqueira W, Walt D, Oppenheim F (2011) Whole-saliva proteolysis and its impact on salivary diagnostics. J Dent Res 90:1325-1330

18. Diaz-Arnold AM, Marek CA (2002) The impact of saliva on patient care: a literature review. J Prosthet Dent 88:337-343

19. Lofroth G (1989) Environmental tobacco smoke: overview of chemical composition and genotoxic components. Mutat Res/ Genet Toxicol 222:73-80

20. Bartal M (2001) Health effects of tobacco use and exposure. Monaldi Arch Chest Dis 56:545-554

21. Dejmek J, Solansk I, Podrazilova K, Sram RJ (2002) The exposure of nonsmoking and smoking mothers to environmental tobacco smoke during different gestational phases and fetal growth. Environ Health Perspect 110:601-606

22. Kupka MS, Dorn C, Richter O, Schmutzler A, van der Ven H, Kulczycki A (2003) Stress relief after infertility treatmentspontaneous conception, adoption and psychological counselling. Eur J Obstet Gynecol Reprod Biol 110:190-195

23. Knackstedt MK, Hamelmann E, Arck PC (2005) Mothers in stress: consequences for the offspring. Am J Reprod Immunol 54:63-69

24. Gyorffy Z, Adam S, Kopp M (2005) Health status of physicians in Hungary: a representative study. Orvosi Hetilap 146:1383-1391

25. Nelson DB, Grisso JA, Joffe MM, Brensinger C, Shaw L, Datner E (2003) Does stress influence early pregnancy loss? Ann Epidemiol 13:223-229

26. Milad MP, Klock SC, Moses S, Chatterton R (1998) Stress and anxiety do not result in pregnancy wastage. Hum Reprod 13:2296-2300

27. Pruessner J, Wolf O, Hellhammer D, Buske-Kirschbaum A, Von Auer K, Jobst S, Kaspers F, Kirschbaum C (1997) Free cortisol levels after awakening: a reliable biological marker for the assessment of adrenocortical activity. Life Sci 61:2539-2549

28. Meulenberg EPMM, Hofman J (1990) The effect of pretreatment of saliva on steroid hormone concentrations. Clin Chem Lab Med 28:923-928

29. Kudielka B, Buske-Kirschbaum A, Hellhammer D, Kirschbaum C (2004) HPA axis responses to laboratory psychosocial stress in healthy elderly adults, younger adults, and children: impact of age and gender. Psychoneuroendocrinology 29:83-98 